\title{
Gray platelet syndrome and defective thrombo-inflammation in Nbeal2-deficient mice
}

\author{
Carsten Deppermann, ${ }^{1}$ Deya Cherpokova, ${ }^{1}$ Paquita Nurden, ${ }^{1,2}$ Jan-Niklas Schulz, ${ }^{3}$ Ina Thielmann, ${ }^{1}$ \\ Peter Kraft, ${ }^{4}$ Timo Vögtle,, ${ }^{1}$ Christoph Kleinschnitz, ${ }^{4}$ Sebastian Dütting, ${ }^{1}$ Georg Krohne, ${ }^{5}$ \\ Sabine A. Eming, ${ }^{3,6,7}$ Alan T. Nurden, ${ }^{2}$ Beate Eckes, ${ }^{3}$ Guido Stoll, ${ }^{4}$ \\ David Stegner, ${ }^{1,4}$ and Bernhard Nieswandt ${ }^{1}$
}

\begin{abstract}
${ }^{1}$ Department of Experimental Biomedicine, University of Würzburg, University Hospital and Rudolf Virchow Center, DFG Research Center for Experimental Biomedicine, Würzburg, Germany. 2Plateforme Technologique et d'Innovation Biomédicale, Hôpital Xavier Arnozan, Pessac, France. ${ }^{3}$ Department of Dermatology, University of Cologne, Cologne, Germany. ${ }^{4}$ Department of Neurology and ${ }^{5}$ Biocenter, University of Würzburg Würzburg, Germany. ${ }^{6}$ Center for Molecular Medicine and ${ }^{7}$ Cologne Excellence Cluster on Cellular Stress Responses in Aging Associated Diseases, University of Cologne, Cologne, Germany.
\end{abstract}

\begin{abstract}
Platelets are anuclear organelle-rich cell fragments derived from bone marrow megakaryocytes (MKs) that safeguard vascular integrity. The major platelet organelles, $\alpha$-granules, release proteins that participate in thrombus formation and hemostasis. Proteins stored in $\alpha$-granules are also thought to play a role in inflammation and wound healing, but their functional significance in vivo is unknown. Mutations in NBEAL2 have been linked to gray platelet syndrome (GPS), a rare bleeding disorder characterized by macrothrombocytopenia, with platelets lacking $\alpha$-granules. Here we show that $\mathrm{Nbeal2}$-knockout mice display the characteristics of human GPS, with defective $\alpha$-granule biogenesis in MKs and their absence from platelets. Nbeal2 deficiency did not affect MK differentiation and proplatelet formation in vitro or platelet life span in vivo. Nbeal2-deficient platelets displayed impaired adhesion, aggregation, and coagulant activity ex vivo that translated into defective arterial thrombus formation and protection from thrombo-inflammatory brain infarction following focal cerebral ischemia. In a model of excisional skin wound repair, Nbeal2-deficient mice exhibited impaired development of functional granulation tissue due to severely reduced differentiation of myofibroblasts in the absence of $\alpha$-granule secretion. This study demonstrates that platelet $\alpha$-granule constituents are critically required not only for hemostasis but also thrombosis, acute thrombo-inflammatory disease states, and tissue reconstitution after injury.
\end{abstract}

\section{Introduction}

Platelet activation and aggregation at sites of vessel wall injury are crucial to prevent posttraumatic blood loss but may also be major participants in diseases such as myocardial infarction and stroke $(1,2)$. Inhibition of platelet function is an important strategy for prevention and treatment of ischemic diseases (3). Platelet activation results in shape change, functional upregulation of integrin receptors, and the release from dense granules ( $\delta$-granules) and $\alpha$-granules whose contents amplify the activation response and promote thrombus formation and stability. While $\delta$-granules contain small, nonprotein molecules, such as calcium, serotonin, $\mathrm{ADP}$, and ATP, that promote platelet aggregation, platelet $\alpha$-granules store a large number of proteins that upon release can support platelet adhesiveness (e.g., VWF, fibrinogen), inflammation (e.g., P-selectin, IL-1 $\beta$, IL-8, platelet factor 4 [CXCL4]), and angiogenesis (e.g., VEGF, FGF-2, PDGF) (4). Wound repair is affected at the earliest and at multiple later stages of the repair process by different platelet products $(5,6)$. Platelet aggregation limits blood loss following injury, VEGF-A stimulates reepithelialization (7) and angiogenesis (8), PDGF attracts fibroblasts to the wound site and stimulates their proliferation (9), and TGF- $\beta 1$ limits immune cell proliferation and extravasation into tissues (10). However,

Conflict of interest: The authors have declared that no conflict of interest exists. Citation for this article: J Clin Invest. 2013;123(8):3331-3342. doi:10.1172/JCI69210. the exact contribution of this plethora of $\alpha$-granule proteins to thrombotic and thrombo-inflammatory processes and wound healing has not been established, mostly because many of them are also released by other cells.

The gray platelet syndrome (GPS) is a rare congenital platelet disorder characterized by the lack of $\alpha$-granules and their contents in platelets of affected individuals. Rudimentary $\alpha$-granule precursors have been detected in platelets and megakaryocytes (MKs) of patients with GPS, indicating that the basic defect in GPS is the inability of MKs to package endogenously synthesized or endocytosed proteins into developing $\alpha$-granules $(11,12)$. Platelets of patients with GPS appear gray and enlarged in the light microscope and may aggregate poorly upon stimulation with thrombin and collagen (13). In addition, most patients with GPS show mild thrombocytopenia, splenomegaly, myelofibrosis, and a mild to moderate bleeding tendency, although rare cases of severe hemorrhage have also been reported $(12,14,15)$.

The genetic defect causing GPS has long remained unknown despite several attempts to establish a murine model mimicking the GPS phenotype (16-18). Only recently, different mutations in the neurobeachin-like 2 (NBEAL2) gene have been identified in patients with GPS (19-21). NBEAL2 is a 302-kDa large member of the BEACH-WD40 domain protein family. Other members of this family, such as neurobeachin, Nbeal1, Lrba, and Lyst, have been associated with protein trafficking $(19,22)$. In contrast to neuro- 

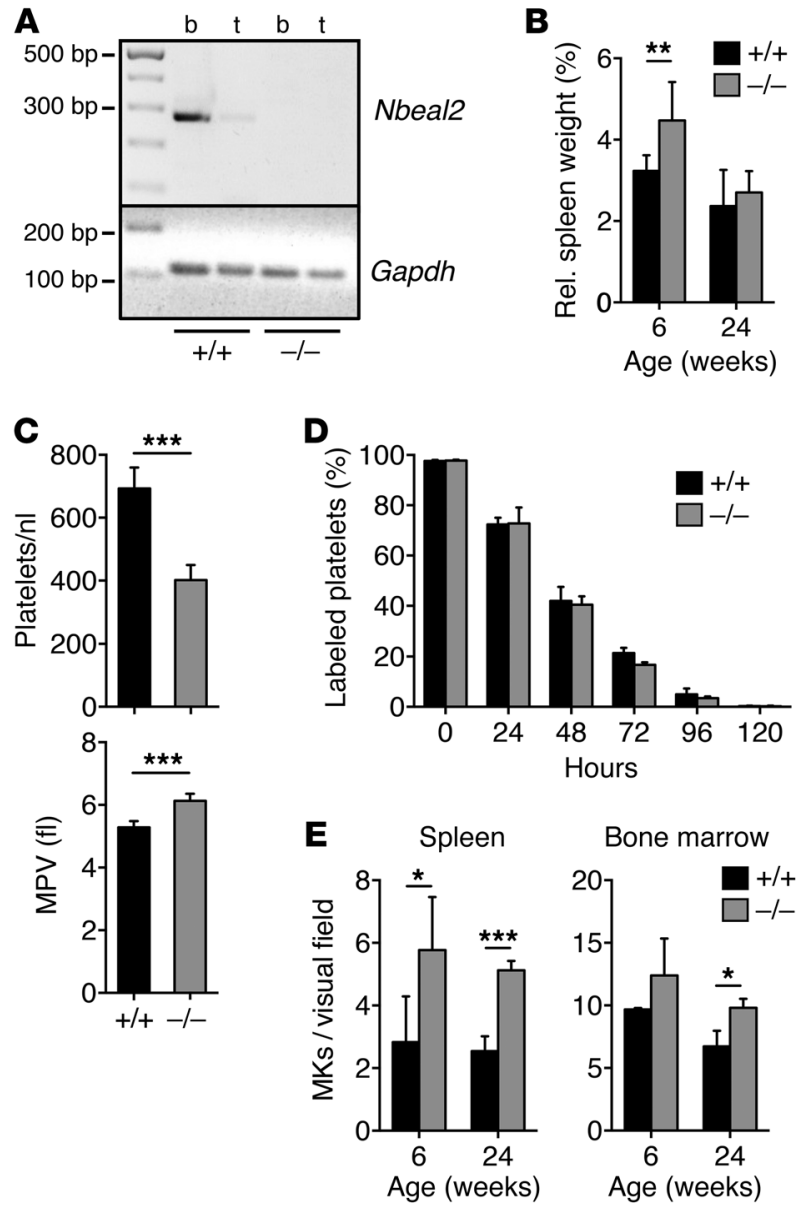

beachin, which is prominently expressed in brain tissue and known to be required for the formation and functioning of central synapses in mice (23), NBEAL2 is highly expressed in blood cells, especially during MK maturation, but virtually absent from brain tissue (19).

Despite the extensive knowledge on $\alpha$-granule contents and the multiple roles for biologically active proteins secreted from platelets, relatively little is known about the importance of the $\alpha$-granule contents in maintaining hemostasis or of their contribution to arterial thrombosis as well as thrombo-inflammatory and wound healing processes.

Here we show for the first time that $\mathrm{Nbeal2}^{-{ }^{--}}$mice display a GPSlike phenotype characterized by a paucity of $\alpha$-granules in platelets and MKs, resulting in impaired platelet adhesion and aggregation in vitro, which translates into a profound protection in murine in vivo models of arterial thrombosis and stroke as well as in a dramatic hemostatic defect and impaired healing of skin wounds.

\section{Results}

To investigate the function of NBEAL2 in platelet biogenesis and hemostasis, we disrupted the Nbeal2 gene in mice. The absence of Nbeal2 mRNA in different tissues was confirmed by RT-PCR (Figure 1A). Nbeal2 ${ }^{-/-}$mice were born in expected Mendelian ratios (data not shown), developed normally, were viable and fertile, and showed no signs of spontaneous bleeding. A mild splenomegaly was observed in 6-week-old mice, which did not develop further within the following 5 months (Figure 1B).

\section{Figure 1}

$\mathrm{Nbeal} 2^{-/-}$mice are macrothrombocytopenic and lack platelet $\alpha$-granules. (A) Analysis of Nbeal2 mRNA in bone marrow (b) and thymus (t) in wild-type $(+/+)$ and $\mathrm{Nbeal}^{-/-}(-/-)$mice. Gapdh mRNA served as loading control. (B) Spleen to body weight ratio was analyzed in 6-week-old and 6-month-old mice. Values are mean $\pm \operatorname{SD}(n=4)$. (C) Peripheral platelet counts and mean platelet volume (MPV) in wild-type and $\mathrm{Nbea}^{-/-}$mice. Values are mean $\pm \mathrm{SD}(n=7)$. (D) Platelet life span as measured by injection of DyLight $488 \alpha$-GPIX. (E) Determination of MK numbers per visual field $(294 \times 221 \mu \mathrm{m})$ in H\&E-stained spleen and bone marrow sections of 6-week-old and 6-month-old mice. Values are mean $\pm \mathrm{SD}(n=4) .{ }^{\star} P<0.05 ;{ }^{* \star} P<0.01 ;{ }^{* \star *} P<0.001$.

Nbeal2-1- mice are macrothrombocytopenic and lack $\alpha$-granules in MKs and platelets. Nbeal2 $2^{-/}$mice displayed a moderate macrothrombocytopenia, with platelet size increased by approximately $14 \%$ and count reduced by approximately $40 \%$ (Figure 1C). Basic blood parameters, such as red/white blood cell count and hemoglobin concentration as well as immune cell populations (B cells, $\mathrm{T}$ cells, granulocytes), were unaltered (Table 1). The in vivo life span of $\mathrm{Nbeal2}^{-/-}$platelets was similar to that of wild-type platelets, excluding increased platelet turnover as a major cause of thrombocytopenia (Figure 1D). Expression levels of major platelet surface receptors were comparable to those of wild-type receptors, except for a slight elevation of GPIb, GPIX, $\alpha \operatorname{IIb} \beta 3$, and CD9 expression, which corresponded well with the increased size of the platelets (Table 1). Analysis of the bone marrow and spleen revealed an almost 2 -fold increase in the number of splenic MKs and a minor increase in the number of bone marrow MKs in both young and 6-month-old $\mathrm{Nbeal2}^{-/-}$mice (Figure 1E). Transmission electron microscopy analysis confirmed the absence of $\alpha$-granules in platelets of $\mathrm{Nbeal2}^{-/-}$mice, whereas $\delta$-granules were not affected. Nbeal2 ${ }^{-/-}$platelets showed increased numbers of vacuoles, which appeared empty, with no electron-dense material inside (Figure 2, $\mathrm{A}$ and $\mathrm{B}$ ). In rare cases, we found structures reminiscent of $\alpha$-granule remnants that were partially filled with diffuse electron-dense material, which is in agreement with observations in patients with GPS (24). Immunofluorescent staining of VWF in spread platelets showed the typical localization in the central body of wildtype platelets, whereas the protein was virtually undetectable in Nbeal2 $^{-/-}$platelets (Figure 2C). Quantification of the platelet VWF content confirmed that Nbeal2 ${ }^{-/}$platelets contain only $11 \%$ of the wild-type level of VWF (Figure 2D).

Platelet territories in mature bone marrow MKs from Nbeal2-/mice contained no characteristic $\alpha$-granules, as seen for the wildtype mice, while the numbers of vacuoles and mitochondria were elevated (Figure 3A, top row). We frequently observed leukocytes inside the cytoplasm of Nbeal2-/- MKs, a process called emperipolesis (Figure 3A, bottom left), a finding also seen in human GPS (25). The demarcation membrane system of Nbeal2-/- MKs was normally developed, with homogeneously distributed delimiting territories, and proplatelet formation was largely unaltered (Figure $3 \mathrm{~A}$, bottom right). Confocal microscopy revealed unaltered actin cytoskeleton and microtubular structures of proplatelet-forming fetal liver cell-derived Nbeal2 ${ }^{-/}$MKs (Figure 3B). We also found no significant differences in the number of proplatelet-forming MKs between wild-type and Nbeal2 ${ }^{-/-}$mice.

Labeling of fetal liver cell- and bone marrow-derived MKs for VWF revealed a diffuse distribution in wild-type controls (Figure 3C), whereas Nbeal2 ${ }^{--}$MKs either lacked VWF or showed accu- 
Table 1

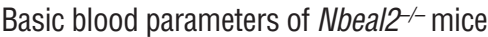

\begin{tabular}{|c|c|c|c|}
\hline & Nbeal2++ & Nbeal2-/- & Significance \\
\hline wbc $\left(\times 10^{3} / \mu l\right)$ & $6.3 \pm 2.5$ & $7.5 \pm 2.8$ & NS \\
\hline rbc $\left(\times 10^{6} / \mu \mathrm{l}\right)$ & $6.8 \pm 0.7$ & $7.2 \pm 1.6$ & NS \\
\hline $\mathrm{HGB}(\mathrm{g} / \mathrm{dl})$ & $10.6 \pm 1.0$ & $12.2 \pm 2.4$ & NS \\
\hline HCT $(\%)$ & $36.2 \pm 3.5$ & $40.1 \pm 9.8$ & NS \\
\hline GPIb (MFI) & $325 \pm 9$ & $365 \pm 4$ & $P<0.01$ \\
\hline GPV (MFI) & $261 \pm 9$ & $268 \pm 5$ & NS \\
\hline GPIX (MFI) & $362 \pm 9$ & $410 \pm 11$ & $P<0.001$ \\
\hline CD9 (MFI) & $1,149 \pm 18$ & $1,226 \pm 44$ & $P<0.05$ \\
\hline GPVI (MFI) & $43 \pm 1$ & $42 \pm 2$ & NS \\
\hline$\alpha 2$ (MFI) & $47 \pm 3$ & $46 \pm 1$ & NS \\
\hline$\beta 1$ (MFI) & $140 \pm 12$ & $135 \pm 4$ & NS \\
\hline$\alpha \operatorname{llb} \beta 3$ (MFI) & $552 \pm 38$ & $632 \pm 37$ & $P<0.01$ \\
\hline CLEC-2 (MFI) & $112 \pm 8$ & $123 \pm 8$ & NS \\
\hline B cells $(\%)$ & $50.4 \pm 3.6$ & $53.1 \pm 4.9$ & NS \\
\hline CD4+ $T$ cells $(\%)$ & $16.2 \pm 2.5$ & $14.7 \pm 1.4$ & NS \\
\hline CD8+ $\mathrm{T}$ cells (\%) & $9.9 \pm 1.7$ & $11.3 \pm 3.0$ & NS \\
\hline $\mathrm{Gr} 1+\mathrm{CD} 11 \mathrm{~b}+(\%)$ & $7.3 \pm 1.5$ & $8.0 \pm 3.6$ & NS \\
\hline Gr1locD11b+ $(\%)$ & $7.1 \pm 1.8$ & $5.1 \pm 1.2$ & NS \\
\hline Gr1negCD11blo (\%) & $3.4 \pm 2.0$ & $4.0 \pm 1.0$ & NS \\
\hline
\end{tabular}

Basic blood parameters were assessed by analyzing diluted whole blood using a Sysmex hematology analyzer. For other values, diluted whole blood (major platelet glycoproteins) or blood lysed in ACK buffer (immune cells) was analyzed by flow cytometry. Results are expressed as MFI $\pm \mathrm{SD}(n=4$ mice per group) and are representative of 5 independent experiments. HGB, hemoglobin; $\mathrm{HCT}$, hematocrit; $\alpha 2$, integrin $\alpha 2 ; \beta 1$, integrin $\beta 1 ; \alpha \mathrm{llb} \beta 3$, integrin $\alpha$ llb $\beta 3$.

mulation of the protein in distinct cytoplasmic areas between the nucleus and the plasma membrane. These areas often also showed additional irregular deposition of actin, which was not seen in Nbeal2-/- MKs lacking VWF or wild-type MKs. This might indicate that VWF is lost from the cytoplasm of Nbeal2-/- MKs at an early time point during megakaryopoiesis, resulting in platelets devoid of VWF (Figure 3C). Of note, VWF plasma levels and multimer size distribution were indistinguishable between wild-type and Nbeal2-/- mice (Figure 3D and Supplemental Figure 1; supplemental material available online with this article; doi:10.1172/ JCI69210DS1), showing normal endothelial cell synthesis.

To assess activation responses in $\mathrm{Nbeal2}^{-/-}$platelets, flow cytometric analysis using P-selectin surface exposure as a marker of $\alpha$-granule release and integrin $\alpha \operatorname{IIb} \beta 3$ activation was performed with wild-type and mutant platelets. In line with the paucity of $\alpha$-granules, Nbeal2 ${ }^{-/}$platelets showed markedly reduced P-selectin exposure compared with wild-type platelets in response to all tested agonists, whereas integrin $\alpha \operatorname{IIb} \beta 3$ activation was largely unaltered (Figure 4A). Analysis of total integrin $\alpha \operatorname{IIb} \beta 3$ surface levels further revealed that the activation-dependent recruitment of intracellular $\alpha \mathrm{IIb} \beta 3$ pools seen in wild-type controls was reduced in Nbeal2 ${ }^{-/-}$platelets (Figure 4B). Surface expression of other glycoproteins on $\mathrm{Nbeal2}^{-1-}$ platelets after stimulation was largely unaltered compared with that on wild-type platelets (Supplemental Table 1). To study the functional consequences of these combined defects, aggregation responses to different agonists were assessed. Consistent with the previous results and observations in patients with GPS (13), Nbeal2-/- platelets showed reduced aggregation upon stimulation with collagen, collagen-related peptide (CRP), or PAR-4 peptide (Figure 4C). Of interest, ATP release, used as a measure of $\delta$-granule release, was unaltered upon stimulation with thrombin or collagen (Figure 4D).

Defective adhesion and aggregate formation of $\mathrm{Nbeal}^{-/-}$platelets under flow. To examine the consequences of platelet $\alpha$-granule deficiency for thrombus formation under flow, anticoagulated whole blood of $\mathrm{Nbeal2}^{--}$and wild-type mice was perfused over immobilized collagen at a shear rate of $1,700 \mathrm{~s}^{-1}$. In these experiments, blood from $\mathrm{Nbeal2}^{-{ }^{--}}$mice was reconstituted with isolated $\mathrm{Nbeal2}^{-/-}$platelets to adjust platelet numbers to those of wild-type controls. Under these conditions, wild-type platelets adhered to collagen fibers

\section{Figure 2}

Analysis of $\alpha$-granule content in $\mathrm{Nbea/2-/-}$ platelets. (A) Representative transmission electron microscopy images of resting wild-type and $\mathrm{Nbeal}^{-/-}$platelets. Note the lack of $\alpha$-granules in $\mathrm{Nbea}^{-/-}$platelets. AG, $\alpha$-granules; DG, $\delta$-granules; $M$, mitochondria; V, vacuoles. Scale bar: $1 \mu \mathrm{m}$. (B) $\mathrm{Nbea}^{-2^{-/}}$platelet ultrastructure. Scale bar: $0.5 \mu \mathrm{m}$ (left); $0.25 \mu \mathrm{m}$ (right). (C) Analysis of filamentous actin structure (red) and VWF (green) localization in spread (30 minutes on fibrinogen) wild-type and $\mathrm{Nbea}^{-/-}$platelets by confocal microscopy. Arrows indicate residual VWF in $\mathrm{Nbeal2^{-/ }}$ platelets. Scale bar: $7.5 \mu \mathrm{m}$. (D) ELISA of VWF and fibrinogen content in resting wild-type and $\mathrm{Nbeal}^{-/-}$platelets. Data are presented as $\triangle$ OD $450 \mathrm{~nm}-\mathrm{OD} 620 \mathrm{~nm}$ of 4 mice per group, normalized to $V w f^{-1}$ or PBS as control, and are representative of 3 individual experiments.
A
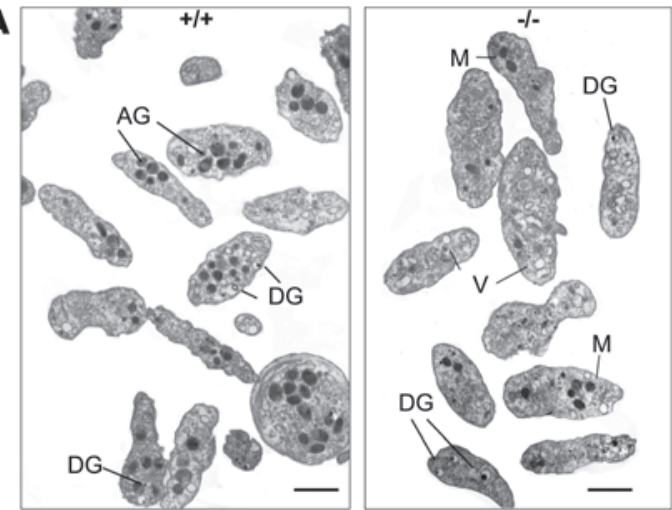

B

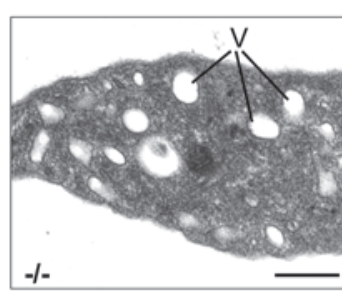

C +

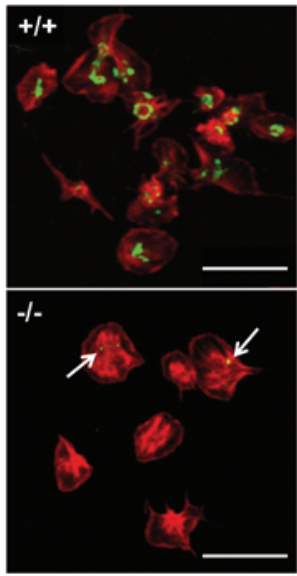

D

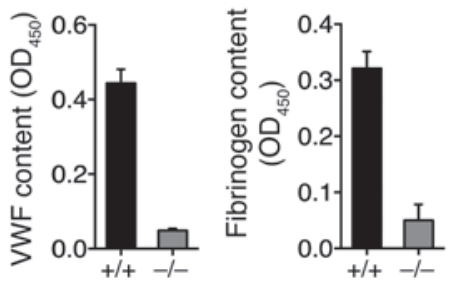


A

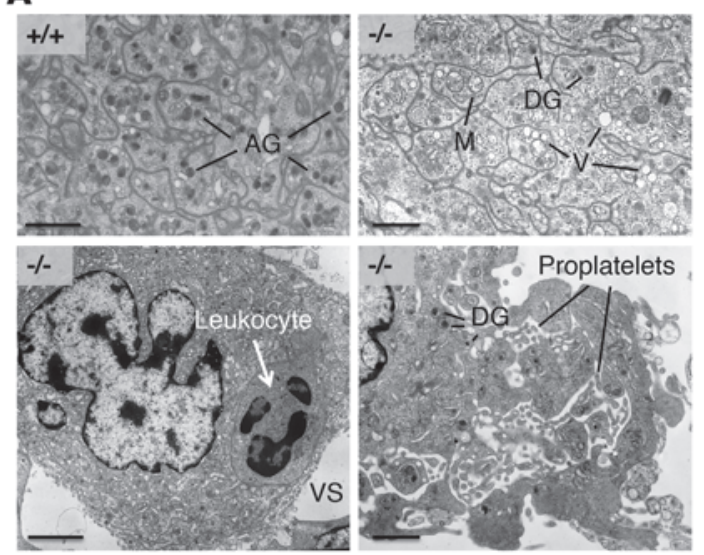

B
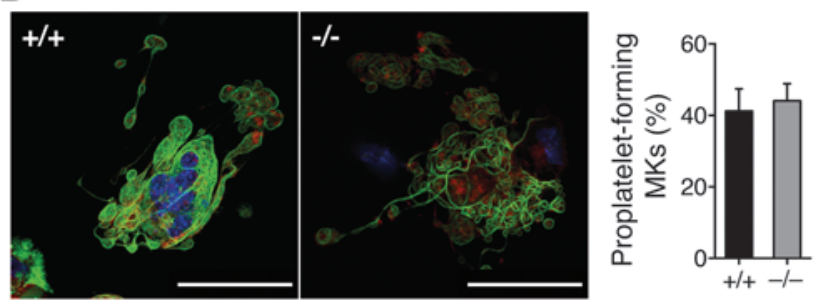

C
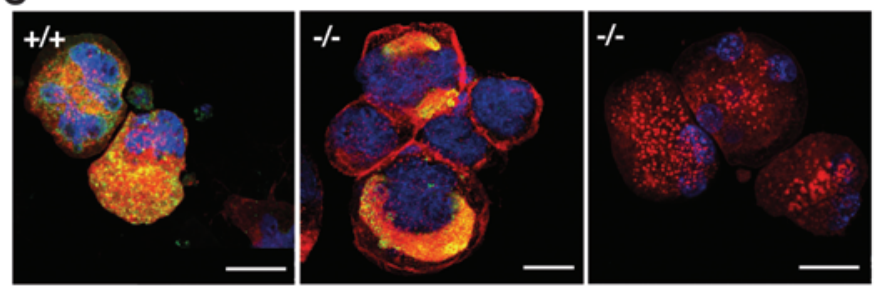

D

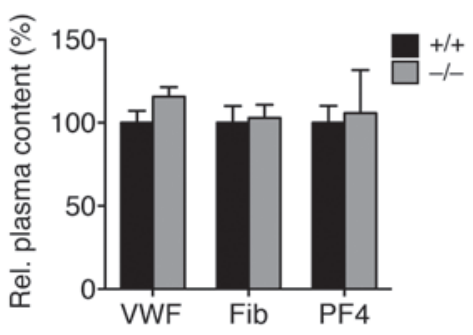

and formed aggregates within 4 minutes that consistently grew into large thrombi by the end of the perfusion period (Figure 5A). In sharp contrast, $\mathrm{Nbeal2}^{-/-}$platelets exhibited reduced adhesion, and 3-dimensional growth of thrombi was markedly impaired. As a consequence, the surface area covered by platelets and the total thrombus volume were reduced by approximately $85 \%$ and approximately $88 \%$, respectively. Similar results were obtained at an intermediate shear rate of $1,000 \mathrm{~s}^{-1}$ (data not shown). These findings indicate that $\alpha$-granular components are required for efficient platelet adhesion on collagen and stable aggregate formation under shear stress.

Activated platelets facilitate coagulation by exposing procoagulant phosphatidylserine (PS) on their outer surface. To determine a possible role of $\alpha$-granules in this process, anticoagulated whole blood from wild-type or $\mathrm{Nbeal2}^{-/-}$mice was perfused over collagen at a shear rate of $1,000 \mathrm{~s}^{-1}$, and PS exposure was determined using

\section{Figure 3}

Paucity of $\alpha$-granules but unaltered ultrastructure in $\mathrm{Nbeal}^{-/-} \mathrm{MKs}$. (A) Representative transmission electron microscopy images of mature bone marrow MKs. Normally developed demarcation membrane system with $\alpha$-granules in a wild-type mouse (top left). Scale bar: $1 \mu \mathrm{m}$. The demarcation membrane system continues to be seen in $\mathrm{Nbeal}^{-/-} \mathrm{MKs}$ (top right) but with a deficiency of $\alpha$-granules and a markedly increased number of vacuoles in $\mathrm{Nbeal}^{-/-}$ MKs. Scale bar: $1 \mu \mathrm{m}$. Note the presence of a leukocyte within the cytoplasm of the mutant MK (bottom left). Scale bar: $3 \mu \mathrm{m}$. Protrusions from the MK cytoplasm and developing proplatelets could be clearly seen in Nbeal2-/- MKs (bottom right). Scale bar: $1 \mu \mathrm{m}$. VS, vascular sinus. (B) Analysis of actin (red) and tubulin-containing (green) structures in fetal liver cell-derived (FLCderived) proplatelet-forming MKs by confocal microscopy. Nuclei were counterstained with DAPI (blue). Proplatelet formation was unaltered in FLC-derived MKs. Results are quantified as the percentage of proplatelet-forming MKs per visual field \pm SD from $\geq 7$ samples per group. Scale bar: $50 \mu \mathrm{m}$. (C) Distribution of VWF (green) in FLC- and bone marrow-derived MKs. Note absence of VWF staining in some $\mathrm{Nbea} / 2^{-/-}$MKs and the accumulation of VWF in other mutant cells, in contrast to a uniform distribution in wild-type MKs. The actin cytoskeleton was visualized using phalloidin (red). Scale bar: $25 \mu \mathrm{m}$. (D) ELISA assay of plasma VWF, fibrinogen, and PF4 content. Data are presented as $\triangle O D 450 \mathrm{~nm}-$ OD $620 \mathrm{~nm}$ of 5 mice per group.

Annexin A5-Dylight 488 staining. Remarkably, the procoagulant index, reflecting PS exposure per covered surface area, was dramatically reduced by 2 orders of magnitude in $\mathrm{Nbeal2-/-}$ platelets compared with that in wild-type controls (Figure 5, B and $\mathrm{C}$ ). This pronounced defect in the coagulant response of $\mathrm{Nbeal2}^{-/-}$platelets was confirmed by flow cytometric analysis of PS exposure to different agonists (Figure 5D). Together, these results revealed that $\alpha$-granules or components thereof are critically required for platelet coagulant activity under shear stress.

Severely defective arterial thrombus formation in $\mathrm{Nbeal2}^{-1-}$ mice. As platelet aggregation may contribute to pathologic occlusive thrombus formation, we studied the effects of NBEAL2 deficiency on ischemia and infarction by in vivo fluorescence microscopy following ferric chloride-induced mesenteric arteriole injury. Nbeal2 ${ }^{-/-}$mice showed an unchanged onset of thrombus formation when compared with wild-type mice, with appearance of first thrombi of more than $10 \mu \mathrm{m}$ approximately 9 minutes after injury in both groups. However, while thrombus formation rapidly progressed to full occlusion in 15 out of 16 wild-type vessels (mean occlusion time: $18.9 \pm 4.3$ minutes), occlusive thrombus formation was markedly impaired in Nbeal2 ${ }^{-1-}$ mice (Figure 6, A and B). This defect was due to the formation of unstable platelet aggregates, which disintegrated rapidly from the vessel wall (Supplemental Videos 1 and 2). Blood flow was maintained throughout the observation period in 10 out of 16 vessels, indicating a critical requirement for $\alpha$-granules during occlusive thrombus formation. This was confirmed in a second arterial thrombosis model, in which the abdominal aorta was mechanically injured and blood flow was monitored with an ultrasonic flow probe. While all wild-type animals examined formed irreversible occlusions within 10 minutes (mean occlusion time: $6.4 \pm 1.7$ minutes), occlusive thrombus formation did not occur in 7 out of 8 Nbeal2 ${ }^{-1-}$ mice during the 30 -minute observation period $(P<0.001)$ (Figure 6, C and D). These results demonstrate that $\alpha$-granules are required for the propagation and stabilization of 
A
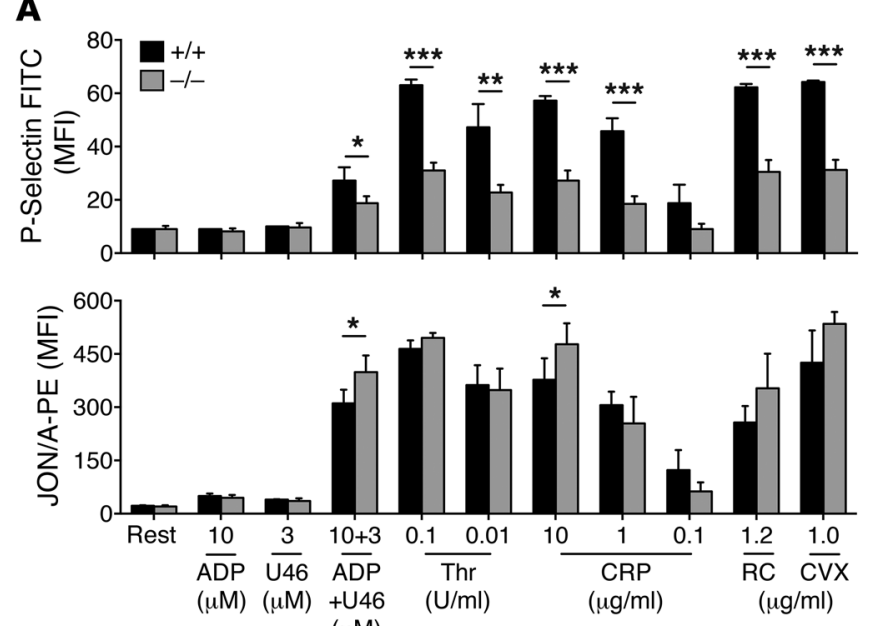

$(\mu \mathrm{M})$
B
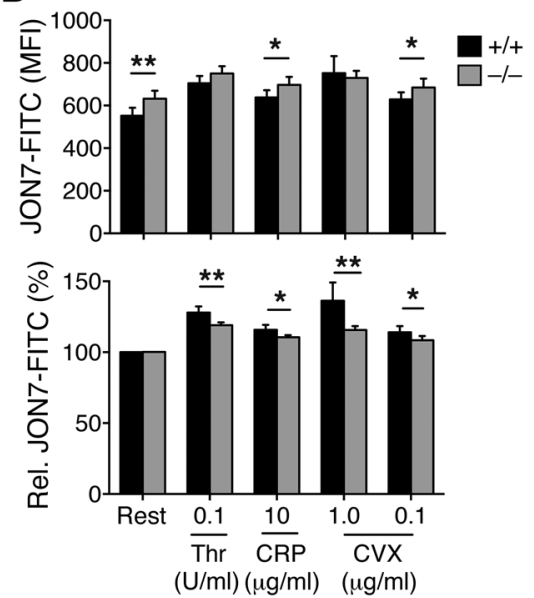

D

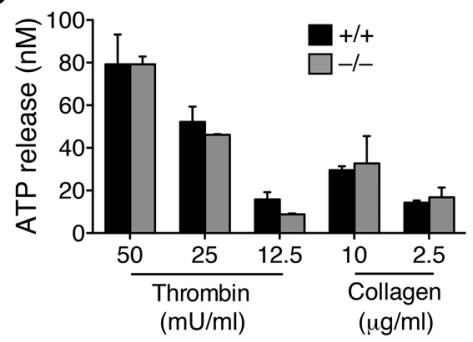

Figure 4

Agonist responses of $\mathrm{Nbeal}^{-/-}$platelets in suspension. (A) Flow cytometric analysis of $\mathrm{Nbeal}^{-/-}$platelets shows decreased degranulation-dependent P-selectin exposure but normal activation of $\alpha$ llb $\beta 3$ integrin (binding of JON/A-PE) upon stimulation with the indicated agonists. (B) Recruitment of integrin $\alpha$ llb $\beta 3$ to the platelet surface upon stimulation with different agonists was assessed using the JON7-FITC antibody. Results in A and B are expressed as MFI \pm SD (top) and mean relative fluorescence intensities \pm SD (bottom) ( $n=4$ mice per group) and are representative of 3 independent experiments. (C) Impaired aggregation of $\mathrm{Nbeal}^{-1-}$ platelets in response to different agonists. Aggregation traces (recording time $=10$ minutes) representative of 2 independent experiments are depicted. (D) Normal ATP release from platelets activated by thrombin and collagen, as assessed by luciferase activity. U46, U46619; Thr, thrombin; RC, rhododcytin; CVX, convulxin; rest, resting. ${ }^{\star} P<0.05$; ${ }^{\star \star} P<0.01$; ${ }^{* \star \star} P<0.001$.

platelet-rich thrombi in small and large arteries and in response to different types of injury.

We next assessed the impact of NBEAL2 deficiency on hemostasis by determining tail bleeding times. While 12 out of 14 wildtype animals arrested bleeding within the observation period of 20 minutes (mean: $460 \pm 178$ seconds), none of the Nbeal2 ${ }^{-1-}$ mice managed to stop bleeding within that time frame (Figure 6E), indicating a strong hemostatic defect. The results from the in vivo thrombosis and hemostasis models were confirmed in irradiated wild-type mice reconstituted with $\mathrm{Nbeal2}^{-/-}$bone marrow (Supplemental Figure 2), demonstrating the importance of NBEAL2 in the hematopoietic system for preventing excessive blood loss and for the formation of stable vessel occluding thrombi in vivo. To further exclude the possibility that NBEAL2 deficiency leads to defects in endothelial cells, we stained different tissues for VWF, an important Weibel-Palade body marker in endothelial cells of different origin. Endothelial cells in wild-type and knockout samples showed a punctate distribution of VWF (Supplemental Figure 3), further indicating a normal synthesis and storage in $\mathrm{Nbeal}^{-1-}$ endothelial cells in line with previous results for patients with GPS (26).

Nbeal2 ${ }^{-1}$ mice are protected in a model of ischemic stroke. Although it is well established that pathological platelet activation contrib- utes to the disturbance of microvascular integrity during cerebral ischemia through thrombotic and proinflammatory pathways, the underlying mechanisms have not been fully elucidated (27). To determine the importance of platelet $\alpha$-granules in this process, we studied the development of neuronal damage following transient cerebral ischemia in Nbeal2 ${ }^{-/-}$mice using a model that depends on platelet adhesion and activation in microvessels downstream from the middle cerebral artery (MCA) (28). To initiate transient cerebral ischemia, a thread was advanced through the carotid artery into the MCA and allowed to remain for 1 hour (transient MCA occlusion [tMCAO]), reducing regional cerebral flow by $>90 \%$ (29). Infarct volumes were assessed by 2,3,5-triphenyltetrazolium chloride staining 24 hours after reperfusion. Infarct size was significantly reduced in $\mathrm{Nbeal2}^{-/-}$mice compared with that in the wild-type mice $\left(40.9 \pm 10.5 \mathrm{~mm}^{3}\right.$ versus $\left.87.29 \pm 9.0 \mathrm{~mm}^{3} ; P<0.01\right)$ (Figure 7, A and B). The difference in infarct volume was functionally relevant, as the Bederson score assessing global neurological function $(1.5 \pm 0.2$ versus $2.9 \pm 0.3$, respectively; $P<0.01)$ and the grip test, which measures motor function and coordination $(4.0 \pm 0.3$ versus $2.4 \pm 0.6$, respectively; $P<0.05)$, were significantly better in $\mathrm{Nbeal2}^{-/-}$mice compared with controls (Figure 7, $\mathrm{C}$ and D). Irradiated wild-type mice reconstituted with $\mathrm{Nbeal2}^{-1-}$ bone 
A
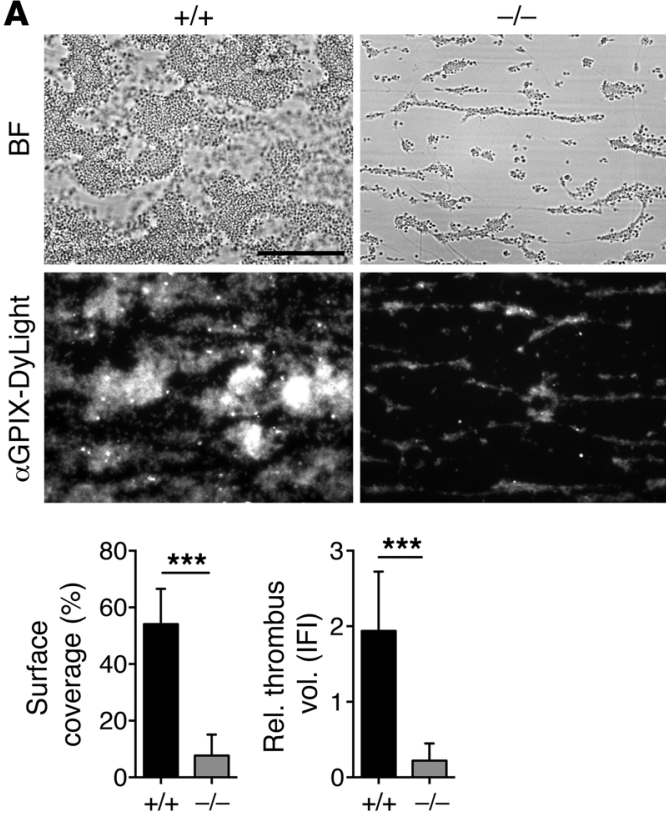

B
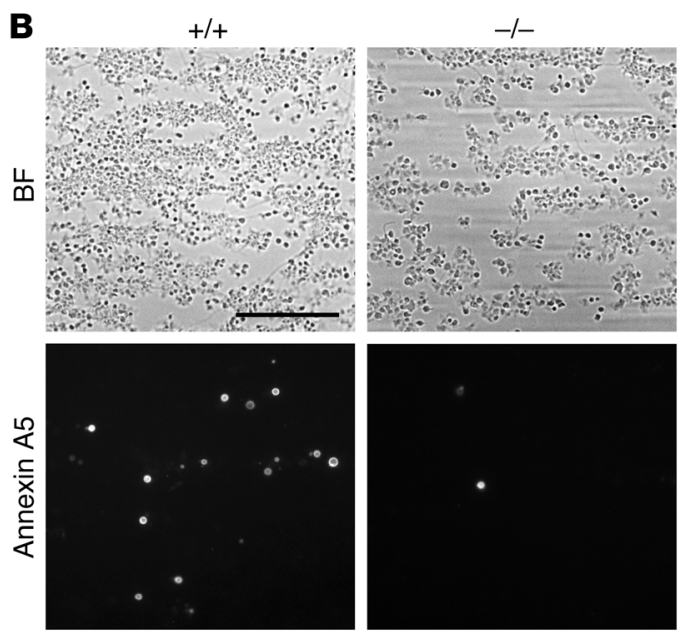

C

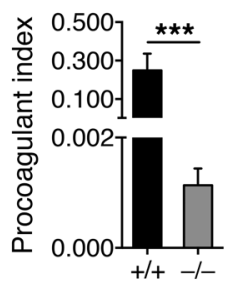

D

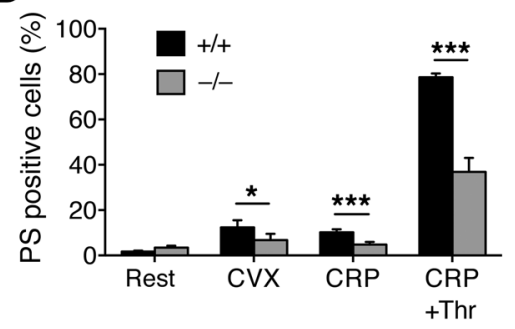

\section{Figure 5}

Nbeal2-/- platelets show defective adhesion, thrombus formation, and PS exposure under flow. (A) Severely impaired adhesion and thrombus formation of $\mathrm{Nbeal2}^{--}$- platelets on collagen under flow at a shear rate of 1,700 s-1. Representative phase-contrast (bright field [BF]) and fluorescence images are shown as well as mean surface coverage and relative platelet deposition, as measured by integrated fluorescent intensity (IFI) per $\mathrm{mm}^{2} \pm \mathrm{SD}$ ( $n=4$ mice per group). Scale bar: $50 \mu \mathrm{m}$. (B) Representative phase-contrast (BF) and fluorescence images of $\mathrm{Nbeal2^{-/ }}$ platelets stained with Annexin A5-DyLight 488 perfused over a collagen-coated surface at a shear rate of 1,000 s-1. Scale bar: $65 \mu \mathrm{m}$. (C) Procoagulant index represents the ratio of Annexin A5-positive cells to surface coverage ( $n=5$ mice per group). (D) Highly diluted washed platelets were stimulated with $1 \mu \mathrm{g} / \mathrm{ml}$ convulxin, $20 \mu \mathrm{g} / \mathrm{ml}$ CRP, or $20 \mu \mathrm{g} / \mathrm{ml}$ CRP plus $0.1 \mathrm{U} / \mathrm{ml}$ thrombin, and the percentage of Annexin A5-positive cells was determined by flow cytometry $(n=5)$. Data are representative of 3 independent experiments. ${ }^{\star} P<0.05 ;{ }^{* \star \star} P<0.001$.

marrow developed small infarcts comparable to those of Nbeal2-mice, whereas wild-type mice transplanted with wild-type bone marrow developed infarcts comparable to those of control wildtype mice (Figure 7). Notably, we found no evidence of intracranial hemorrhage in any of the animals analyzed. These results indicated that platelet $\alpha$-granules are critically required to drive thrombo-inflammatory neuronal damage in the acutely ischemic brain.

Nbeal2-/- mice show impaired dermal healing due to reduced TGF- $\beta$ release from mutant platelets. Platelets are among the first cell types infiltrating sites of injury and crucially contribute to wound hemostasis. In addition, platelets provide essential mediators, which attract neutrophils, macrophages, endothelial cells, and fibroblasts to the wound site $(6,30)$. Platelet $\alpha$-granules contain TGF- $\beta$, which is one of the most abundant mediators that limits immune cell proliferation (10) and is crucially required for the differentiation of myofibroblasts, which produce the majority of extracellular matrix components forming the temporary granulation tissue (31) and ultimately the scar. While the crucial importance of TGF- $\beta$ for a successful healing process is well established, the relative contribution of the platelet-derived pool of this and other growth factors or released $\alpha$-granule constituents is unknown.

To assess the functional significance of $\alpha$-granule-derived mediators for efficient tissue repair, full-thickness wounds com- prising epidermis, dermis, and subcutaneous fat were inflicted on the backs of $\mathrm{Nbeal2}^{--}$mice and littermate control animals. At 7 days after injury, the amount of granulation tissue filling the wound and the presence of myofibroblasts in this tissue were assessed (Figure 8). Routine histological analysis (H\&E) revealed that wounds in both genotypes were fully reepithelialized (Figure $8 \mathrm{~A}$ ); however, the area of the underlying granulation tissue was severely reduced in $\mathrm{Nbeal2}^{---}$wounds compared with that in control wounds $(P<0.01)$ (Figure $8, \mathrm{~B}$ and D). In particular, the collagenous tissue, visualized by picrosirius red stain (Figure 8B), was much less well developed in mutants, while the extent of the neovasculature, detected by CD31 staining, was not altered (data not shown). This suggested either reduced abundance or impaired function of myofibroblasts, the key effector cells elaborating the new dermal matrix. In fact, mutant wounds contained significantly fewer myofibroblasts than controls $(P<0.05$; Figure 8 , C and E), as shown by staining for $\alpha$ SMA, a marker of the myofibroblast contractile microfilament apparatus, indicating impaired myofibroblast differentiation.

As the differentiation of myofibroblasts critically relies on TGF- $\beta$, we speculated that Nbeal2-deficient platelets might not provide sufficient amounts of this mediator. Immunoblotting of control and Nbeal2-deficient platelet lysates confirmed dramatically dimin- 
A
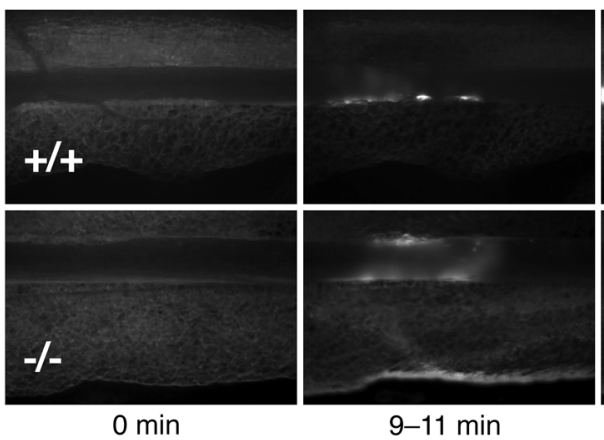

$9-11 \mathrm{~min}$

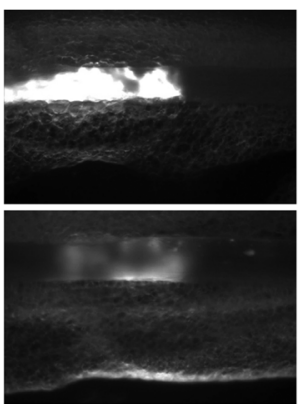

19-21 min

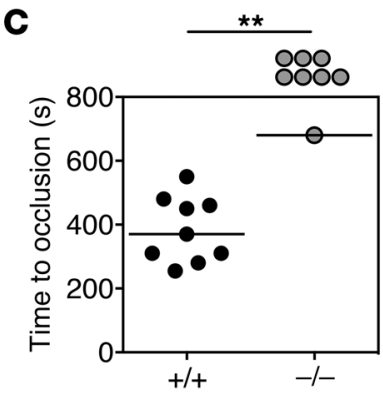

B

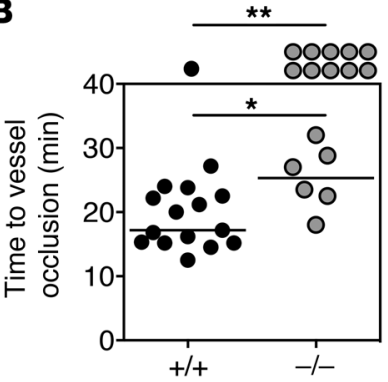

D

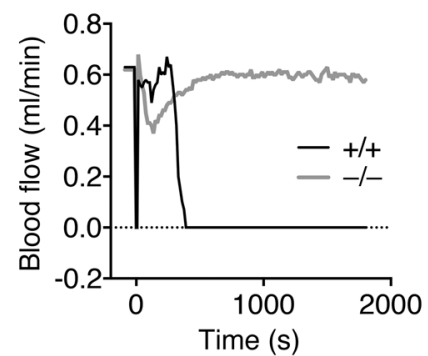

$\mathbf{E}$

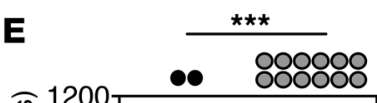

ished amounts $(P<0.001)$ of free, mature TGF- $\beta(12-\mathrm{kDa}$ monomer; Figure 8, F and G) as well as of the pro-TGF- $\beta$ (with its latencyassociated peptide, approximately $50-\mathrm{kDa}$ monomer; Figure $8 \mathrm{~F}$ ).

These results demonstrate for the first time that biologically active proteins released from platelet $\alpha$-granules are crucially required for myofibroblasts to differentiate and produce the matrix proteins (e.g., collagens) reconstituting dermal integrity after injury.

\section{Discussion}

Although the first description of a patient with GPS was reported in 1971 (32), it took until 2011 for NBEAL2 to be identified as the mutated gene causing the disease, a finding which thereby provided the molecular basis for detailed studies on the function and (patho-)physiological significance of $\alpha$-granules, the most abundant organelles in platelets (19-21). Our study now provides compelling complementary evidence that NBEAL2 is essential for platelet $\alpha$-granule biogenesis and establishes the $\mathrm{Nbeal2}^{--/}$mouse as a valuable animal model of GPS that recapitulates many of the symptoms found in patients with GPS. The mice show a moderate thrombocytopenia and a relatively modest increase in platelet size in line with the human phenotype. While earlier studies reported that GPS is a progressive disorder, with platelet counts decreasing with age, no such correlation was seen over the short study period

in the mouse model. Platelet aggregation upon stimulation with PAR-4 peptide, collagen, and CRP was reduced for Nbeal2-deficient platelets, which is in accordance with data from patients with GPS that nonetheless show diversity with respect both to genotype and phenotype (33). Nbeal2 $2^{--}$mice as a model for GPS allow for the first time in vivo studies on the role of $\alpha$-granule proteins in both normal hemostasis and thrombo-inflammatory disease states.

In addition, $\mathrm{Nbeal2}^{-1-}$ mice will serve as a valuable model to study $\alpha$-granule biogenesis, which is still poorly understood. MK-synthesized $\alpha$-granule proteins share a 3 -dimensional granule-targeting motif that is required to properly target them to $\alpha$-granules (34). Our initial studies show the accumulation of $\alpha$-granule proteins at distinct sites inside the MKs, indicating aberrant protein sorting rather than defective protein synthesis, which is in line with observations in patients with GPS (reviewed in ref. 13). It should be emphasized that the Nbeal2-/- mice, like human patients with GPS, show deficiency of all platelet $\alpha$-granule proteins independently of whether the stored proteins are sequestered by endocytosis (e.g., fibrinogen) or, for the most part, synthesized by MKs and independently of the purported distinct packaging of the proteins within different granule subpopulations or within the $\alpha$-granule itself $(35,36)$. Further studies will be required to determine how NBEAL2, which encodes a BEACH/ $\mathrm{ARM} / \mathrm{WD} 40$ domain protein, regulates $\alpha$-granule biogenesis. 
A

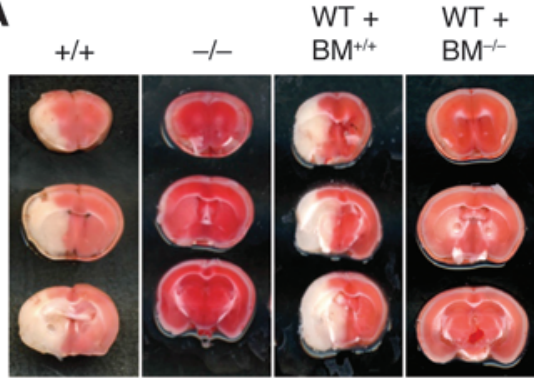

B

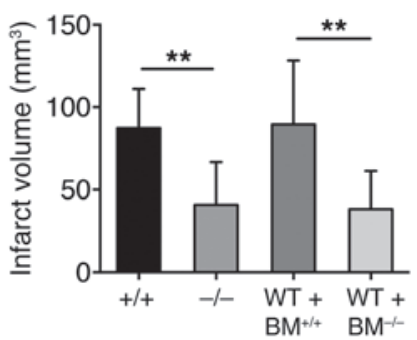

C

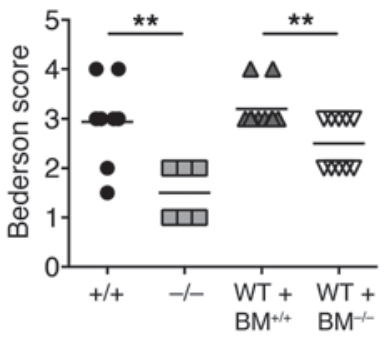

D

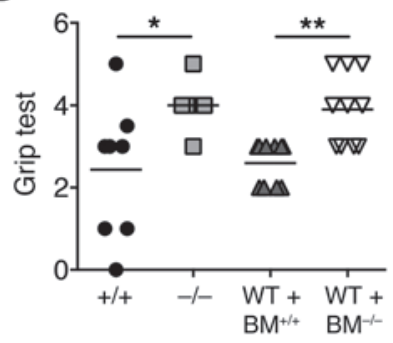

Figure 7

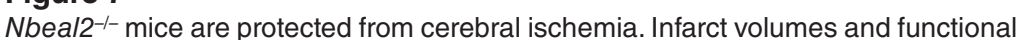
outcome 24 hours after focal cerebral ischemia in wild-type and $\mathrm{Nbea/2}{ }^{-/-}$mice, as well as wild-type mice reconstituted with wild-type and $\mathrm{Nbeal}^{-/-}$bone marrow, were investigated in a murine model of ischemic stroke. Mice were subjected to 60 minutes of tMCAO. (A) Representative images of 3 coronal sections stained with 2,3,5-triphenyltetrazolium chloride 24 hours after tMCAO. (B) Brain infarct volumes $(n \geq 6)$ were measured by planimetry. Results represent mean \pm SD. (C) Bederson score and (D) grip test determined 24 hours after tMCAO. Each symbol represents 1 individual mouse. ${ }^{\star} P<0.05 ;{ }^{*} P<0.01$.

Interestingly, our studies on fetal liver cell-derived MKs revealed no marked abnormality in proplatelet formation, suggesting that the reduced platelet numbers in the mutant mice may be caused by a defect in the terminal steps of platelet production. This suggestion is reinforced by our finding of a normal platelet survival in the Nbeal2 ${ }^{-1-}$ mice. Although platelets from patients with GPS allowed studies on the role of $\alpha$-granules in platelet function tests in vitro, the sometimes severe thrombocytopenia in the human subjects often makes the assessment difficult $(12,13)$. As a consequence, the contribution of secreted adhesive proteins to plateletmediated processes in vivo has remained poorly understood since early reports pointing to roles of fibrinogen and thrombospondin in secretion-dependent platelet aggregation $(37,38)$. Our studies unambiguously show a role of secreted proteins both in platelet aggregation in vitro and in thrombus formation under flow. There is also considerable clinical heterogeneity in human GPS with mild to moderate bleeding tendencies as well as severe life-threatening hemorrhages in rare cases $(12,13,15)$. We found severely prolonged tail bleeding times in Nbeal2 ${ }^{-1}$ mice but no signs of spontaneous hemorrhage. This confirms that there is no direct correlation between bleeding time and bleeding risk (39) and reveals an essential function of $\alpha$-granules in the arrest of posttraumatic bleeding, whereas they appear not be required for the maintenance of vascular integrity in the absence of injury.

Significantly, the platelet aggregation defect of $\mathrm{Nbeal}^{-/-}$platelets translated into a severely defective formation of stable thrombi under conditions of medium and high shear stress (Figure 5A). A similar albeit less pronounced phenotype has been reported previously in different mouse lines, including those lacking CD40 ligand (CD40-L) (40) or the calcium sensor molecule STIM1 (41), with marked defects in thrombus stability under flow in vitro and in vivo despite only mild defects in activation/aggregation in the absence of flow. This suggests that $\alpha$-granulederived mediators and/or adhesion molecules are particularly important to build shear-resistant thrombi under conditions in which agonist potency becomes limited due to rapid dilution and various receptorligand interactions have to be integrated to produce appropriate cell-cell interactions.

Unexpectedly, we found a markedly reduced coagulant activity of $\mathrm{Nbeal2}^{-/-}$platelets, which was not based on impaired agonist receptor function, as indicated by the normal integrin $\alpha \operatorname{IIb} \beta 3$ activation and unaltered $\delta$-granule release responses of the mutant platelets upon stimulation with all tested agonists (Figure 5C and Figure 4, A and D, respectively). This suggests that $\alpha$-granule-derived factors are required for the efficient collapse of the membrane asymmetry and exposure of coagulant PS in platelets activated under flow (42). This $\mathrm{Ca}^{2+}$-dependent process involves the activity of the TMEM16F ion channel $(43,44)$ and is mediated by lipid transporters (scramblases) whose identity and subcellular localization have remained elusive.

While a role for some $\alpha$-granule proteins in hemostasis and thrombosis has been demonstrated, most of them are also present in other vascular compartments, making conclusions on the relative importance of their $\alpha$-granule pool difficult $(2,45)$. One prominent example is VWF, which is also present at high concentrations in Weibel-Palade bodies of endothelial cells and in plasma. We found that $\mathrm{Nbeal2}^{-/-}$mice, lacking VWF in platelets but not in plasma or endothelium (Figure 2, B and C, Figure 3D, and Supplemental Figure 3), displayed severely defective platelet adhesion and aggregate formation on collagen under high shear flow conditions, a process known to depend on GPIb-VWF interactions (46). This indicates that $\alpha$-granule VWF is of central importance for the formation of shear-resistant thrombi under these experimental conditions but also that multiple other $\alpha$-granule proteins, including fibrinogen and thrombospondin and possibly also vitronectin and fibronectin (47), probably contribute to this process. In line with this, the thrombus formation defect observed in $\mathrm{Nbeal2}^{-/-}$mice in vivo appeared to be more severe than that seen in mice lacking VWF (ref. 48 and data not shown), P-selectin (49), or CD40-L (40). It is unlikely that the reduced platelet count in $\mathrm{Nbeal2}^{-/-}$mice was responsible for their hemostatic and thrombotic defect, as we have recently shown that both hemostasis and thrombosis are largely unaffected by equivalent platelet count reductions in mice (50).

Significantly, Nbeal2 ${ }^{-/}$mice or chimeric mice lacking NBEAL2 in the hematopoietic system were profoundly protected from tMCAO-induced brain infarction (Figure 7), indicating that platelet $\alpha$-granule components are critical pathogenic factors in this setting. The lack of platelet VWF may not be critical here, as plasma VWF has been shown to be sufficient to promote infarct growth in this model (51). This reveals that different VWF pools contribute to very distinct (patho-)physiological processes and indicates that other 
A
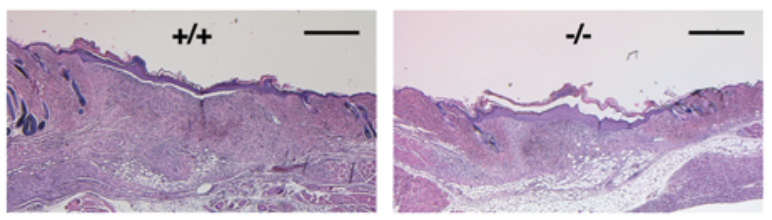

B
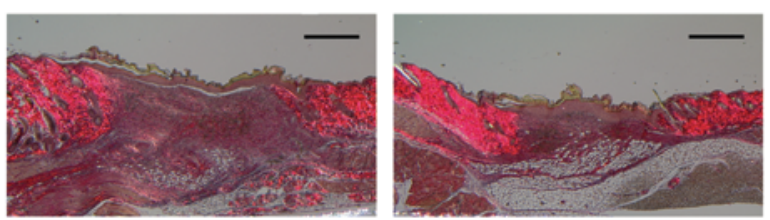

C
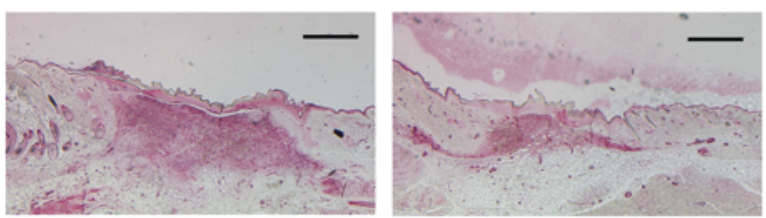

D

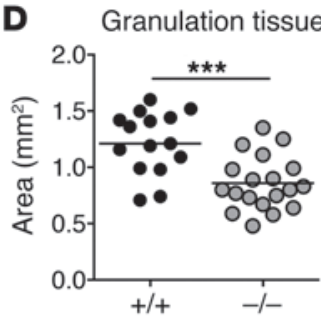

$\mathbf{F}$

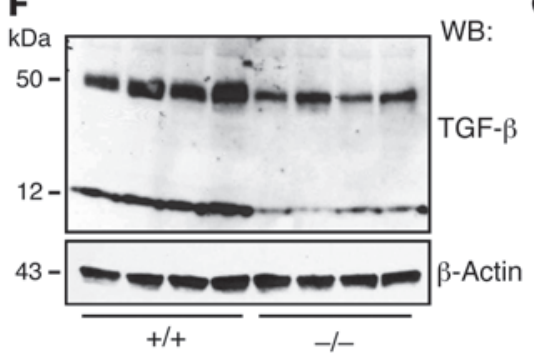

G

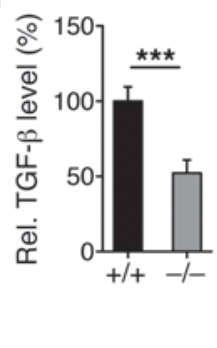

$\alpha$-granule components are critical to promote thrombo-inflammation in the ischemic brain. On the other hand, despite markedly prolonged bleeding times, we did not observe intracranial bleeding in Nbeal2 $2^{-/}$mice after tMCAO, suggesting that the $\alpha$-granule storage pool of adhesion molecules is not required to maintain vascular integrity under conditions of acute inflammation (52).

The relevance of platelets and their products for successful tissue reconstitution is reflected in the use of platelet-rich plasma (PRP) to promote healing (53-55). However, rendering mice thrombocytopenic leads to increased wound inflammation without affecting the reparative aspects of wound repair (56). A recent study demonstrated better healing responses in diabetic mice injected with nonactivated versus thrombin-activated platelets; the authors concluded that platelets may be used as cell therapy rather than exploited for their growth factor content (57). The approach that we have taken preserved the cells and ablated the defined spectrum of growth factors specifically contained in platelet $\alpha$-granules. Our results clearly demonstrate for the first time the crucial importance of platelet-derived proteins, released during the first hours after injury, for myofibroblast differentiation, which peaks at 7 days after

\section{Figure 8}

Impaired dermal repair due to reduced myofibroblast activity in wounds of $\mathrm{Nbeal2-deficient} \mathrm{mice} \mathrm{and} \mathrm{severely} \mathrm{diminished} \mathrm{mature} \mathrm{and} \mathrm{pro-}$ TGF- $\beta$ in Nbeal2-deficient platelets. (A-C) Representative sections of wounds at 7 days after injury. Wounds of Nbeal2-deficient mice display (A) reduced development of granulation tissue but similar epithelial wound closure (H\&E staining), (B) reduced amounts of collagenous granulation tissue (central darker area in picrosirius red stain), (C) and severely diminished myofibroblast numbers per wound. Scale bar: 500 $\mu \mathrm{m}$. (D) Area of granulation tissue is significantly reduced in mutants ( $n=19)$ versus that in wild-type mice $(n=15)$. (E) Area occupied by $\alpha$ SMA-positive myofibroblasts is significantly diminished in mutants $(n=20)$ versus that in controls $(n=16)$. (F) Reduced amounts of mature TGF- $\beta$ monomer $(12 \mathrm{kDa})$ and of pro-TGF- $\beta$ monomer (50 $\mathrm{kDa}$ ) in lysates from Nbeal2-deficient versus wild-type platelets (corresponding to $6 \times 106$ platelets each). (G) Densitometric evaluation of TGF- $\beta$ signals ( $12+50 \mathrm{kDa}$ ), normalized to $\beta$-actin signals. $n=4$ for each genotype. ${ }^{*} P<0.05 ;{ }^{* \star} P<0.001$.

wounding. This result implies that TGF- $\beta$ released by macrophages, which are abundantly present throughout the inflammatory and reparative phases of healing (30), does not compensate for early deficiency due to platelet dysfunction. At 7 days after wounding we did not detect differences in wound macrophage numbers (data not shown). Detailed characterization of the early inflammatory infiltrate will show whether their numbers differ at earlier time points in the healing process; however, large differences might have resulted in vascular abnormalities (58), which we did not detect. To investigate whether NBEAL2 deficiency affects other hematopoietic cells, we analyzed Nbeal2 expression in lymphocytes, splenocytes, and $\mathrm{CD} 4^{+} \mathrm{T}$ cells by $\mathrm{qPCR}$. We found very low expression levels in these cells when compared with MKs (data not shown), thereby confirming results from previous studies (19). However, further conclusions on the possible role for NBEAL2 in other cells in the healing process will require the preparation of conditional mouse models. Likewise, defining the roles of TGF- $\beta$ relative to other secreted proteins will require extensive studies on multiple mouse models.

Taken together, our study provides direct evidence that NBEAL2 is essential for $\alpha$-granule biogenesis in MKs and that these organelles are critically required to efficiently arrest posttraumatic bleeding but not to maintain vascular integrity in the absence of injury. On the other hand, the absence of $\alpha$-granules provides profound protection from occlusive arterial thrombus formation and thrombo-inflammatory brain infarction in the setting of acute stroke. Lack of $\alpha$-granule secretion specifically impairs the development of abundant scar tissue following injury, an observation that may prove useful in conditions in which fibrotic scar tissue impairs tissue function and in which its development should be antagonized.

These findings may have important implications for the development of novel antithrombotic and antiinflammatory therapies, while the Nbeal2 ${ }^{--}$mice will offer a novel opportunity to study the role of $\alpha$-granule proteins in angiogenesis and in other pathological processes said to involve platelets, such as tumorigenesis and metastasis.

\section{Methods}

Mice. Nbeal2 ${ }^{+/-}$mice on a C57BL/6J background, in which exons 4 through 11 were targeted by homologous recombination, were obtained from MMRRC (University of California, Davis) and intercrossed to generate Nbeal2 ${ }^{-/}$mice. 6- to 10-week-old mice were used for experiments, unless otherwise stated. Animal studies were approved by the district government of Lower Frankonia (Bezirksregierung Unterfranken). 
Generation of bone marrow chimeric mice. 6-week-old recipient C57BL/6 mice were lethally irradiated with a single dose of $10 \mathrm{~Gy}$, and bone marrow cells from wild-type or $\mathrm{Nbeal2}^{-/-}$mice were injected i.v. into the irradiated mice $\left(4 \times 10^{6}\right.$ cells per mouse). All recipient mice received water containing $2 \mathrm{~g} / \mathrm{l}$ neomycin sulfate for 2 weeks after transplantation. Nbeal2 mRNA deficiency was confirmed by RT-PCR.

Antibodies and reagents. Anesthetic drugs (medetomidine [Pfizer], midazolam [Roche], fentanyl [Janssen-Cilag]) and antagonists (atipamezol [Pfizer], flumazenil and naloxon [both purchased from Delta Select]) were used according to the regulations of the local authorities. High-molecular-weight heparin (Ratiopharm), apyrase grade III (Sigma-Aldrich), indomethacin (Sigma-Aldrich), prostacyclin $\left(\mathrm{PGI}_{2}\right), \mathrm{ADP}$ (Sigma-Aldrich), U-46619 (Enzo Life Sciences), thrombin (Roche), collagen (Kollagenreagens Horm; Nycomed), convulxin (Enzo Life Sciences), PAR-4-activating peptide (Thermo Fisher Scientific), human fibrinogen (Sigma-Aldrich), rabbit anti-human VWF (DAKO), rabbit anti-human fibrinogen (DAKO), rabbit anti-FITC-HRP (DAKO), rabbit anti-human VWF-HRP (DAKO), mouse anti- $\alpha$-tubulin Alexa Fluor 488 (clone B-5-1-2, Molecular Probes), phalloidin-Atto647N (Fluka), DAPI (Invitrogen), IMDM (Invitrogen), penicillin/streptomycin (Invitrogen), thrombopoietin (Invitrogen), FCS (Perbio), recombinant hirudin (Refludan, Baxter Healthcare Corporation), and rat anti-mouse CD29 ( $\beta 1$ integrin) (BD Biosciences) were purchased as indicated. CRP was generated as previously described (59). Rhodocytin was isolated as previously described (60). The antibody against the activated form of integrin $\alpha \operatorname{IIb} \beta 3$ (JON/A-PE) was from Emfret Analytics. All other antibodies were generated and modified in our laboratory as previously described (61).

RT-PCR. mRNA from thymus and bone marrow was isolated using TRIzol reagent (Invitrogen), and cDNA was synthesized using SuperScript reverse transcriptase (Invitrogen) according to the manufacturer's protocol. The following primers were used to detect the NBEAL2 transcript: 5'-GGACCCAGCTAGAGAACGTG-3' and 5'-CATCTGCCCATTCGCCTTTC-3'. The expected product size was $275 \mathrm{bp}$. The primers used for detection of the GAPDH transcript were 5'-GCAAAGTGGAGATTGTTGCCAT- $3^{\prime}$ and $5^{\prime}$-CCTTGACTGTGCCGTTGAATTT- $3^{\prime}$, and the expected product size was $108 \mathrm{bp}$.

Platelet preparation. Mice were bled under isoflurane anesthesia from the retro-orbital plexus. Blood was collected in a tube containing $20 \mathrm{U} / \mathrm{ml}$ heparin, and PRP was obtained by 2 cycles of centrifugation at $300 \mathrm{~g}$ for 6 minutes at room temperature (RT). For preparation of washed platelets, PRP was washed twice at $800 \mathrm{~g}$ for 5 minutes at RT and the pellet was resuspended in modified Tyrodes-HEPES (N-2-hydroxyethyl-piperazone-N'2-ethanesulfonic acid) buffer (134 mM NaCl, $0.34 \mathrm{mM} \mathrm{Na}_{2} \mathrm{HPO}_{4}$, $2.9 \mathrm{mM} \mathrm{KCl}, 12 \mathrm{mM} \mathrm{NaHCO}_{3}, 5 \mathrm{mM}$ HEPES, $1 \mathrm{mM} \mathrm{MgCl}_{2}, 5 \mathrm{mM}$ glucose, $0.35 \% \mathrm{BSA}, \mathrm{pH} 7.4)$ in the presence of prostacyclin $(0.1 \mu \mathrm{g} / \mathrm{ml})$ and apyrase $(0.02 \mathrm{U} / \mathrm{ml})$. Platelets were then resuspended in modified Tyrodes-HEPES buffer containing $2 \mathrm{mM} \mathrm{CaCl}_{2}$ and $0.02 \mathrm{U} / \mathrm{ml}$ apyrase.

Fluorescent labeling of $\alpha$-granule proteins in spread platelets. Washed platelets were activated with $0.1 \mathrm{U} / \mathrm{ml}$ thrombin and spread for 30 minutes on slides coated with $100 \mu \mathrm{g} / \mathrm{ml}$ fibrinogen. Platelets were fixed using $1 \%$ PFA in PHEM buffer (100 mM PIPES, $5.25 \mathrm{mM}$ HEPES, $10 \mathrm{mM}$ EGTA, $20 \mathrm{mM} \mathrm{MgCl}$ ), stained with anti-human-VWF-FITC and phalloidin-Atto647N (Fluka), and visualized using a Leica TCS SP5 confocal microscope (Leica Microsystems).

Culture of MKs derived from fetal liver progenitor cells. Fetal livers were isolated on embryonic day 13.5 to 14.5 from time-mated females. Livers were homogenized, and cells were cultured in IMDM medium supplemented with $10 \% \mathrm{FCS}, 1 \%$ penicillin/streptomycin, and $50 \mathrm{ng} / \mathrm{ml}$ thrombopoietin at $37^{\circ} \mathrm{C}, 5 \% \mathrm{CO}_{2}$. On day 3 , MKs were enriched by a 2 -step density gradient filtration with $1.5 \%$ and $3 \%$ BSA. On day 4 , the percentage of proplateletforming MKs was determined using a light microscope.
Culture of MKs derived from bone marrow progenitor cells. Hematopoietic stem cells were isolated by flushing bone marrow cells from femurs of 6- to 8-week-old male mice followed by a negative selection using a MACS system (Miltenyi Biotec) with the Dynal Mouse T Cell Negative Isolation Kit according to the manufacturer's protocol (Invitrogen). Cells were cultured in IMDM medium supplemented with $10 \%$ FCS, $1 \%$ penicillin/streptomycin, $50 \mathrm{ng} / \mathrm{ml}$ thrombopoietin, and $50 \mu \mathrm{g} / \mathrm{ml}$ recombinant hirudin at $37^{\circ} \mathrm{C}$, $5 \% \mathrm{CO}_{2}$ for 3 days, prior to MK purification using a $1.5 \%-3 \%$ BSA gradient.

Fluorescent staining of MKs. Cultured MKs were spun down onto a microscope slide using a cytocentrifuge (Cytospin, Thermo Scientific), fixed in $4 \%$ PFA, and permeabilized with $1 \%$ Igepal. $\alpha$-Granule VWF was stained with an anti-VWF-FITC antibody. Tubulin was visualized using an anti- $\alpha$-tubulin antibody (clone B-5-1-2, Molecular Probes), and polymerized actin was stained with phalloidin-Atto647N (Fluka). MKs were visualized using a Leica TCS SP5 confocal microscope (Leica Microsystems) and further processed with ImageJ software (NIH).

Quantification of VWF, fibrinogen, and PF4 content by ELISA. Heparinized plasma or washed platelets at a concentration of $5 \times 10^{5}$ platelets/ $\mu$ l were lysed in buffer (15 mM TRIS/HCl, pH 8.0, $155 \mathrm{mM} \mathrm{NaCl}, 1 \mathrm{mM}$ EDTA) containing $1 \%$ Igepal, incubated for 20 minutes at $4{ }^{\circ} \mathrm{C}$, and centrifuged 5 minutes at 22,000 $\mathrm{g}$. For determination of VWF or fibrinogen content, ELISA plates were coated with $10 \mu \mathrm{g} / \mathrm{ml}$ rabbit anti-human VWF or $10 \mu \mathrm{g} / \mathrm{ml}$ rabbit anti-human fibrinogen antibody, respectively, overnight at $4^{\circ} \mathrm{C}$ and blocked with $5 \%$ BSA. Sample dilutions were incubated for 2 hours at $37^{\circ} \mathrm{C}$. After washing with TBS $0.1 \%$ Tween, samples were incubated with HRPcoupled rabbit anti-human VWF antibody $(1: 3,000)$. For the fibrinogen ELISA detection was performed using rabbit anti-human fibrinogen-FITCFab fragments and, subsequently, rabbit anti-FITC-HRP (1:1,000). After washing, ELISAs were developed using TMB ONE substrate, and plates were read at $450 \mathrm{~nm}$. Previous experiments showed that the anti-VWF antibodies recognized mouse VWF. The amount of plasma PF4 was quantified by a PF4 ELISA (RayBiotech).

Transmission electron microscopy of resting platelets. Washed platelets were fixed with $2.5 \%$ glutaraldehyde in $0.1 \mathrm{M}$ cacodylate buffer, $\mathrm{pH} 7.2$, and embedded in Epon. Thin sections were stained with $2 \%$ uranyl acetate (in $100 \%$ ethanol) and lead citrate and examined under an EM900 transmission electron microscope (Carl Zeiss) (62).

Transmission electron microscopy of bone marrow MKs. Femurs of 6- to 8-week-old mice were flushed with Karnovsky fixative, incubated overnight at $4{ }^{\circ} \mathrm{C}$, fixed with $2 \%$ osmium tetroxide in $50 \mathrm{mM}$ sodium cacodylate $(\mathrm{pH}$ 7.2), and stained with $0.5 \%$ aqueous uranyl acetate. Upon dehydration with ethanol and embedding in Epon 812, ultrathin sections were stained with $2 \%$ uranyl acetate (in $100 \%$ ethanol) followed by lead citrate. Samples were analyzed on a Zeiss EM900 transmission electron microscope (Zeiss) (62).

Platelet aggregation. Washed platelets $\left(50 \mu \mathrm{l}\right.$ with $5 \times 10^{5}$ platelets $\left./ \mu \mathrm{l}\right)$ were diluted into $110 \mu$ Tyrode-HEPES buffer containing $2 \mathrm{mM} \mathrm{Ca}^{2+}$ and $100 \mu \mathrm{g} / \mathrm{ml}$ human fibrinogen. Agonists were added at the indicated concentrations to the continuously stirred $(1,000 \mathrm{rpm})$ platelet suspension. Light transmission was recorded on a Fibrintimer 4-channel aggregometer (APACT Laborgeräte und Analysensysteme) for 10 minutes and was expressed in arbitrary units with buffer representing $100 \%$ transmission and washed platelet suspension or PRP $0 \%$ transmission, respectively.

Flow cytometry. A total of $50 \mu \mathrm{l}$ heparinized blood was diluted 1:20 and incubated for 12 minutes at RT with saturating amounts of fluorophorelabeled antibodies for determination of platelet surface glycoprotein expression. Alternatively, samples were washed twice in Tyrode-HEPES buffer without $\mathrm{Ca}^{2+}$, diluted in Tyrode-HEPES buffer containing $2 \mathrm{mM} \mathrm{CaCl}_{2}$, activated with agonists at the indicated concentrations, stained with fluorophore-conjugated monoclonal antibodies at saturating concentrations for 10 minutes at $37^{\circ} \mathrm{C}$, and analyzed on a FACSCalibur flow cytometer (BD Biosciences). 
ATP release. Washed platelets $\left(80 \mu \mathrm{l}\right.$ with $5 \times 10^{5}$ platelets $\left./ \mu \mathrm{l}\right)$ were diluted into $160 \mu$ Tyrode-HEPES buffer containing $2 \mathrm{mM} \mathrm{Ca}^{2+}$. After addition of $25 \mu \mathrm{l}$ luciferase reagent (CHRONO-LUME), agonists were added at indicated concentrations to the continuously stirred (1,000 rpm) platelet suspension. Light transmission and luminescence were recorded on a 700 Whole Blood/Optical Lumi-Aggregometer (Chrono-log) for 10 minutes and were expressed in arbitrary units with buffer representing $100 \%$ transmission and washed platelet suspension or PRP $0 \%$ transmission, respectively. ATP release was calculated by the AggroLink 8 software using an ATP standard.

Platelet adhesion to collagen under flow. Rectangular cover slips $(24 \times 60$ $\mathrm{mm}$ ) were coated with $200 \mu \mathrm{g} / \mathrm{ml}$ fibrillar type I collagen (Nycomed) and blocked with $1 \%$ BSA. Heparinized whole blood was labeled with DyLight 488-conjugated anti-GPIX Ig derivative $(0.2 \mu \mathrm{g} / \mathrm{ml})$ and perfused over collagen-coated coverslips through transparent flow chamber at a shear rate of $1,700 \mathrm{~s}^{-1}$ or $1,000 \mathrm{~s}^{-1}$ as previously described (63). Phase-contrast and fluorescence images were obtained from at least 7 different collagencontaining microscopic fields for each sample using a Zeiss Axiovert 200 inverted microscope ( $\times 40$ objective; Carl Zeiss) and analyzed off-line using Metavue software (Visitron).

Quantification of PS exposure. Heparinized whole blood was supplemented with an additional $10 \mathrm{U} / \mathrm{ml}$ heparin. Adhesion experiments under flow conditions (shear rate $1,000 \mathrm{~s}^{-1}$ ) were performed as described above. The flow chamber was rinsed for 4 minutes with Tyrode-HEPES buffer containing $2 \mathrm{mM} \mathrm{CaCl}_{2}, 10 \mathrm{U} / \mathrm{ml}$ heparin, and $0.25 \mu \mathrm{g} / \mathrm{ml}$ Annexin A5DyLight 488. The flow chamber was rinsed for an additional 2 minutes with Tyrode-HEPES buffer supplemented with $2 \mathrm{mM} \mathrm{CaCl}_{2}$ and $10 \mathrm{U} / \mathrm{ml}$ heparin, before phase-contrast and fluorescence images were obtained using a Zeiss Axiovert 200 inverted microscope (Carl Zeiss). Image analysis was performed off-line using Metavue software (Visitron).

Determination of platelet life span. Mice were injected i.v. with DyLight 488conjugated $\alpha$-GPIX ( $0.5 \mu \mathrm{g} / \mathrm{g}$ body weight). $50 \mu \mathrm{l}$ of blood was collected 60 minutes after injection (day 0 ) and each day thereafter for 5 days. The percentage of fluorescently labeled platelets was analyzed by flow cytometry.

Tail bleeding time. Mice were anesthetized, and a 2-mm segment of the tail tip was removed using a scalpel. Tail bleeding was monitored by gently absorbing blood on filter paper at 20-second intervals without making contact with the wound site. Bleeding was determined to have ceased when no blood was observed on the paper. Experiments were stopped after 20 minutes.

Intravital microscopy of thrombus formation in $\mathrm{FeCl}_{3}$-injured mesenteric arterioles. Four-week-old mice were anesthetized, and the mesentery was exteriorized through a midline abdominal incision. Arterioles (35- to 60- $\mu \mathrm{m}$ diameter) were visualized with a Zeiss Axiovert 200 inverted microscope ( $\times 10 / 0.3 \mathrm{NA}$ objective) (Carl Zeiss) equipped with a 100-W HBO fluorescent lamp source and a CoolSNAP-EZ camera (Visitron). Digital images were recorded and analyzed off-line using Metavue software. Injury was induced by topical application of a $3-\mathrm{mm}^{2}$ filter paper saturated with $20 \% \mathrm{FeCl}_{3}$ for 10 seconds. Adhesion and aggregation of fluorescently labeled platelets (DyLight 488conjugated $\alpha$-GPIX) in arterioles were monitored for 40 minutes or until complete vessel occlusion occurred (blood flow stopped for $>1$ minutes).

Aorta occlusion model. The abdominal cavities of anesthetized mice were opened by a longitudinal incision. An ultrasonic flow probe (Transonic Flowprobe 0.5, Transonic Systems) was placed around the exposed abdominal aorta, and thrombosis was induced by a single firm 15 -second compression with forceps. Blood flow was monitored until complete blood vessel occlusion occurred for a minimum of 5 minutes. Otherwise the experiments were stopped manually after 30 minutes.

$t M C A O$ model. Focal cerebral ischemia was induced by $t \mathrm{MCAO}$ as described previously (29). Briefly, a thread was advanced through the carotid artery into the MCA to reduce cerebral blood flow and removed after 60 minutes to allow reperfusion. The extent of infarction was quantitatively assessed 24 hours after reperfusion on 2,3,5-triphenyltetrazolium chloride-stained brain sections. Global neurological function was evaluated by the Bederson score. Motor function and coordination were assessed by the grip test.

Wounding and tissue harvesting. Two full-thickness wounds (6-mm punch biopsies) comprising the epidermis, dermis, subcutaneous adipose tissue, and panniculus carnosus muscle were inflicted on the shaved backs of anesthetized (10-week-old) mice on either side of the backbone at the scapular region as described previously (64). At 7 days after wounding, complete wounds were removed, bisected, and embedded unfixed in optimal cutting compound (Sakura) or fixed for 2 hours in 4\% PFA before embedding in paraffin. Experiments were approved by the local veterinary authorities (Landesamt für Natur, Umwelt und Verbraucherschutz North Rhine-Westphalia).

Histology, immunohistochemistry, and immunofluorescence analysis. Sections were cut from the wound center and stained with H\&E or picrosirius red according to standard procedures. The area occupied by newly formed granulation tissue was determined in sections stained with picrosirius red using ImageJ 1.43u (http://rsb.info.nih.gov/ij). Myofibroblasts were visualized on paraffin sections using FITC-conjugated clone 1A4 (Sigma-Aldrich), followed by rabbit anti-fluorescein (A889, Molecular Probes) and biotinylated anti-rabbit IgG (Vectastain ABC Kit, Vector Laboratories) as described before (65). Vascular structures were stained on cryosections using antibodies directed to CD31 (MEC13.3, BD Biosciences) and desmin (D33, Dako).

Determination of TGF- $\beta$ levels in platelets. Washed platelets were lysed in RIPA buffer (150 mM NaCl, $50 \mathrm{mM}$ Tris, 1\% NP-40, 0.1\% SDS, $12 \mathrm{mM}$ desoxycholate) with protease inhibitors (Roche). Equal amounts of lysate were applied to SDS-PAGE gradient gels (4\%-12\%, Bio-Rad) under reducing conditions and blotted to Hybond C extra membranes (Amersham Biosciences). Recombinant human latent TGF- $\beta 1$ (R\&D Systems) was used as positive control. Membranes were incubated with an antibody recognizing TGF- $\beta 1$ and TGF- $\beta 3$ (56E4, Cell Signaling Technology Inc.). Similar loading was confirmed by reblotting the membranes for $\beta$-actin (sc47778, Santa Cruz Biotechnology Inc.).

Statistics. Results are shown as mean \pm SD from 3 individual experiments per group, unless indicated otherwise. Statistical analysis was conducted using the unpaired Student's $t$ test, apart from the Fischer's exact test, which was applied to assess variance between nonoccluded arteries, and the Mann-Whitney $U$ test, which was used for analysis of Bederson score and grip test after tMCAO. $P$ values of less than 0.05 were considered statistically significant. Supplemental Methods are available online.

\section{Acknowledgments}

We thank Jonas Müller for excellent technical assistance, Sabine Herterich for help with VWF multimer analysis, Sabine Walter and Heike Hermanns for help with qRT-PCR, and Shuchi Gupta for help with microscopy. This work was supported by the DFG (SFB 688 to B. Nieswandt and G. Stoll, SFB 829 to B. Eckes and S.A. Eming) and the Rudolf Virchow Center. C. Deppermann was supported by a grant of the German Excellence Initiative to the Graduate School of Life Sciences, University of Würzburg.

Received for publication February 5, 2013, and accepted in revised form May 10, 2013.

Address correspondence to: Bernhard Nieswandt or David Stegner, University Hospital Würzburg and Rudolf Virchow Center, DFG Research Center for Experimental Biomedicine, University of Würzburg, Josef-Schneider-Str. 2, 97080 Würzburg, Germany. Phone: 49.931.31.80405; Fax: 49.931.201.61652; E-mail: bernhard. nieswandt@virchow.uni-wuerzburg.de (B. Nieswandt), stegner@ virchow.uni-wuerzburg.de (D. Stegner). 
1. Furie B, Furie BC. Mechanisms of thrombus formation. N Engl J Med. 2008;359(9):938-949.

2. Jackson SP. Arterial thrombosis--insidious, unpredictable and deadly. Nat Med.2011;17(11):1423-1436.

3. Bhatt DL, Topol EJ. Scientific and therapeutic advances in antiplatelet therapy. Nat Rev Drug Discovery. 2003;2(1):15-28.

4. Blair P, Flaumenhaft R. Platelet $\alpha$-granules: basic biology and clinical correlates. Blood Rev. 2009 23(4):177-189.

5. Nurden A. Platelets, inflammation and tissue regeneration. Thromb Haemost. 2011;105(6):S13-S33.

6. Werner S, Grose R. Regulation of wound healing by growth factors and cytokines. Physiol Rev. 2003; 83(3):835-870.

7. Wilgus TA, et al. Novel function for vascular endothelial growth factor receptor-1 on epidermal keratinocytes. Am J Pathol. 2005;167(5):1257-1266.

8. Eming SA, Krieg T. Molecular mechanisms of VEGF-A action during tissue repair. J Investig Dermatol Symp Proc. 2006;11(1):79-86

9. Seppä H, Grotendorst G, Seppa S, Schiffmann E, Martin GR. Platelet-derived growth factor is chemotactic for fibroblasts. J Cell Biol. 1982;92(2):584-588.

10. Kulkarni AB, et al. Transforming growth factor beta 1 null mutation in mice causes excessive inflammatory response and early death. Proc Natl Acad Sci U S A. 1993;90(2):770-774.

11. Rosa J, George J. Gray platelet syndrome. Demonstration of alpha granule membranes that can fuse with the cell surface. J Clin Invest. 1987;80(4):1138-1146.

12. Gunay-Aygun M, et al. Gray platelet syndrome: natural history of a large patient cohort and locus assignment to chromosome 3p. Blood. 2010; 116(23):4990-5001.

13. Nurden AT, Nurden P. The gray platelet syndrome: clinical spectrum of the disease. Blood Rev. 2007; 21(1):21-36

14. Jantunen E, Hänninen A, Naukkarinen A, Vornanen M, Lahtinen R. Gray platelet syndrome with splenomegaly and signs of extramedullary hematopoiesis: a case report with review of the literature. Am J Hematol. 1994;46(3):218-224.

15. Gootenberg J, Buchanan G. Severe hemorrhage in a patient with gray platelet syndrome. J Pediatr. 1986; 109(6):1017-1019.

16. Stenberg PE, et al. Prolonged bleeding time with defective platelet filopodia formation in the Wistar Furth rat. Blood. 1998;91(5):1599-1608.

17. Wang Y, et al. Pleiotropic platelet defects in mice with disrupted FOG1-NuRD interaction. Blood. 2011; 118(23):6183-6191.

18. Kimura Y, et al. Zinc finger protein, Hzf, is required for megakaryocyte development and hemostasis. J Exp Med. 2002;195(7):941-952.

19. Albers CA, et al. Exome sequencing identifies NBEAL2 as the causative gene for gray platelet syndrome. Nat Genet. 2011;43(8):735-737.

20. Kahr WH, et al. Mutations in NBEAL2, encoding a BEACH protein, cause gray platelet syndrome. Nat Genet. 2011;43(8):738-740.

21. Gunay-Aygun M, et al. NBEAL2 is mutated in gray platelet syndrome and is required for biogenesis of platelet $\alpha$-granules. Nat Genet. 2011;43(8):732-734.

22. Wang $X$, et al. Neurobeachin: A protein kinase A-anchoring, beige/Chediak-higashi protein homolog implicated in neuronal membrane traffic. J Neurosci. 2000;20(23):8551-8565.

23. Medrihan L, et al. Neurobeachin, a protein implicated in membrane protein traffic and autism, is required for the formation and functioning of central synapses. J Physiol. 2009;587(21):5095-5106.

24. Maynard DM, Heijnen HFG, Gahl WA, GunayAygun $\mathrm{M}$. The $\alpha$-granule proteome: novel proteins in normal and ghost granules in gray platelet syndrome. J Thromb Haemost. 2010;8(8):1786-1796.
25. Falik-Zaccai TC, et al. A new genetic isolate of gray platelet syndrome (GPS): clinical, cellular, and hematologic characteristics. Mol Genet Metab. 2001; 74(3):303-313.

26. Gebrane-Younès J, Cramer EM, Orcel L, Caen JP. Gray platelet syndrome. Dissociation between abnormal sorting in megakaryocyte alpha-granules and normal sorting in Weibel-Palade bodies of endothelial cells. J Clin Invest. 1993;92(6):3023-3028.

27. Nieswandt B, Kleinschnitz C, Stoll G. Ischaemic stroke: a thrombo-inflammatory disease? J Physiol. 2011;589(17):4115-4123.

28. Stoll G, Kleinschnitz C, Nieswandt B. Molecular mechanisms of thrombus formation in ischemic stroke: novel insights and targets for treatment. Blood. 2008;112(9):3555-3562.

29. Kleinschnitz C, et al. Targeting platelets in acute experimental stroke: impact of glycoprotein Ib, VI, and IIb/IIIa blockade on infarct size, functional outcome, and intracranial bleeding. Circulation. 2007; 115(17):2323-2330

30. Eming SA, Hammerschmidt M, Krieg T, Roers A. Interrelation of immunity and tissue repair or regeneration. Semin Cell Dev Biol. 2009;20(5):517-527.

31. Tomasek JJ, Gabbiani G, Hinz B, Chaponnier C, Brown RA. Myofibroblasts and mechano-regulation of connective tissue remodelling. Nat Rev Mol Cell Biol. 2002;3(5):349-363.

32. Raccuglia G. Gray platelet syndrome. Am J Med. 1971;51(12):818-828

33. Bottega $\mathrm{R}$, et al. Correlation between platelet phenotype and NBEAL2 genotype in patients with congenital thrombocytopenia and $\alpha$-granule deficiency. Haematologica. 2013;98(6):868-874.

34. El Golli N, Issertial O, Rosa J-P, Briquet-Laugier V. Evidence for a granule targeting sequence within platelet factor 4. J Biol Chem. 2005;280(34):30329-30335.

35. Italiano JE, et al. Angiogenesis is regulated by a novel mechanism: pro- and antiangiogenic proteins are organized into separate platelet alpha granules and differentially released. Blood. 2008;111(3):1227-1233.

36. Kamykowski J, Carlton P, Sehgal S, Storrie B. Quantitative immunofluorescence mapping reveals little functional coclustering of proteins within platelet a-granules. Blood. 2011;118(5):1370-1373.

37. Silverstein RL, Leung LL, Nachman RL. Thrombospondin: a versatile multifunctional glycoprotein. Arterioscler Thromb Vasc Biol. 1986;6(3):245-253.

38. Heilmann E, Hourdille P, Pruvost A, Paponneau A, Nurden AT. Thrombin-induced platelet aggregates have a dynamic structure. Time- dependent redistribution of glycoprotein IIb-IIIa complexes and secreted adhesive proteins. Arterioscler Thromb Vasc Biol. 1991;11(3):704-718.

39. Rodgers RP, Levin J. A critical reappraisal of the bleeding time. Semin Thromb Hemost. 1990;16(1):1-20.

40. André $\mathrm{P}$, et al. CD40L stabilizes arterial thrombi by a beta3 integrin - dependent mechanism. Nat Med. 2002;8(3):247-252.

41. Varga-Szabo D, et al. The calcium sensor STIM1 is an essential mediator of arterial thrombosis and ischemic brain infarction. J Exp Med. 2008; 205(7):1583-1591.

42. Heemskerk JWM, Mattheij NJA, Cosemans JMEM. Platelet-based coagulation: different populations, different functions. J Thromb Haemost. 2013;11(1):2-16.

43. Suzuki J, Umeda M, Sims PJ, Nagata S. Calciumdependent phospholipid scrambling by TMEM16F. Nature. 2010;468(7325):834-838.

44. Yang $\mathrm{H}$, et al. TMEM16F Forms a $\mathrm{Ca}(2+)$-activated cation channel required for lipid scrambling in platelets during blood coagulation. Cell. 2012; 151(1):111-122.

45. Sachs UJH, Nieswandt B. In vivo thrombus formation in murine models. Circ Res. 2007;100(7):979-991.

46. Savage B, Almus-Jacobs F, Ruggeri ZM. Specific synergy of multiple substrate-receptor interactions in platelet thrombus formation under flow. Cell. 1998;94(5):657-666

47. Yang H, et al. Fibrinogen and von Willebrand factor-independent platelet aggregation in vitro and in vivo. J Thromb Haemost. 2006;4(10):2230-2237.

48. Denis C, et al. A mouse model of severe von Willebrand disease: defects in hemostasis and thrombosis. Proc Natl Acad Sci US A. 1998;95(16):9524-9529.

49. Falati $S$, et al. Accumulation of tissue factor into developing thrombi in vivo is dependent upon microparticle P-selectin glycoprotein ligand 1 and platelet P-selectin. J Exp Med. 2003;197(11):1585-1598.

50. Morowski M, Vögtle T, Kraft P, Kleinschnitz C, Stoll G, Nieswandt B. Only severe thrombocytopenia results in bleeding and defective thrombus formation in mice [published online ahead of print April 12, 2013]. Blood. doi:10.1182/blood-2012-10-461459.

51. Kleinschnitz C, et al. Deficiency of von Willebrand factor protects mice from ischemic stroke. Blood. 2009;113(15):3600-3603.

52. Goerge T, et al. Inflammation induces hemorrhage in thrombocytopenia. Blood. 2008;111(10):4958-4964.

53. Akingboye A, et al. Application of autologous derived-platelet rich plasma gel in the treatment of chronic wound ulcer: diabetic foot ulcer. J Extra Corpor Technol. 2010;42(1):20-29.

54. Everts $\mathrm{P}$, et al. Is the use of autologous platelet-rich plasma gels in gynecologic, cardiac, and general reconstructive surgery beneficial? Curr Pharm Biotechnol. 2012;13(7):1163-1172.

55. Nurden A, Nurden P, Sanchez M, Andia I, Anitua E. Platelets and wound healing. Front Biosci. 2008; 13:3532-3548.

56. Szpaderska A, Egozi E, Gamelli R, DiPietro L. The effect of thrombocytopenia on dermal wound healing. I Investig Dermatol Symp Proc. 2003; 120(6):1130-1137.

57. Scherer SS, et al. Nonactivated versus thrombin-activated platelets on wound healing and fibroblast-to-myofibroblast differentiation in vivo and in vitro. Plast Reconstr Surg. 2012;129(1):46e-54e.

58. Lucas T, et al. Differential roles of macrophages in diverse phases of skin repair. J Immunol. 2010; 184(7):3964-3977.

59. Knight CG, et al. Collagen-platelet interaction: GlyPro-Hyp is uniquely specific for platelet Gp VI and mediates platelet activation by collagen. Cardiovasc Res. 1999;41(2):450-457.

60. Bergmeier W, et al. Rhodocytin (aggretin) activates platelets lacking alpha(2)beta(1) integrin, glycoprotein VI, and the ligand-binding domain of glycoprotein Ibalpha. J Biol Chem. 2001;276(27):25121-25126.

61. Nieswandt B, Bergmeier W, Schulte V, Rackebrandt $\mathrm{K}$, Gessner JE, Zirngibl H. Expression and function of the mouse collagen receptor glycoprotein VI is strictly dependent on its association with the FcRgamma chain. J Biol Chem. 2000;275(31):23998-24002.

62. Poujol C, Ware J, Nieswandt B, Nurden AT, Nurden P. Absence of GPIbalpha is responsible for aberrant membrane development during megakaryocyte maturation: ultrastructural study using a transgenic model. Exp Hematol. 2002;30(4):352-360.

63. Nieswandt B, et al. Glycoprotein VI but not alpha2beta1 integrin is essential for platelet interaction with collagen. EMBO J. 2001;20(9):2120-2130.

64. Zweers MC, et al. Integrin alpha2beta 1 is required for regulation of murine wound angiogenesis but is dispensable for reepithelialization. J Invest Dermatol. 2007;127(2):467-478.

65. Tomasek JJ, McRae J, Owens GK, Haaksma CJ. Regulation of alpha-smooth muscle actin expression in granulation tissue myofibroblasts is dependent on the intronic CArG element and the transforming growth factor-beta1 control element. Am J Pathol. 2005;166(5):1343-1351 